\title{
ESPAÑA Y ESTADOS UNIDOS EN UN NUEVO CONTEXTO ESTRATÉGICO
}

\author{
David García ${ }^{1}$ \\ Universidad Complutense de Madrid (UCM)/ UNISCI
}

\begin{abstract}
Resumen:
La estrategia de seguridad nacional de 2013 establece una clara continuidad respecto a la estrategia de 2011 respecto al tratamiento de la alianza y las relaciones con EEUU, aspecto positivo que demuestra un acuerdo en una política de Estado fundamental para España. Sin embargo, tiende a ser más un documento de consenso político y declarativo/informativo, que una estrategia de seguridad con mayor calado y profundidad. En este sentido, el análisis y la construcción de la estrategia denota discutibles concepciones y percepciones sobre la estructura del sistema internacional y la conducta de las grandes potencias, que pueden crear narrativas, estrategias y políticas peligrosas en una situación de reducción de capacidades que pueden llevar a un dilema de seguridad. En este sentido, las alianzas y políticas estratégicas de España pueden moverse entre su reforzamiento (chain gangs) o su abandono (buckpassing), incluyendo planificaciones estratégicas más realistas. Una revisión del Convenio de Cooperación para la Defensa dentro del marco de profundización de la Declaración Conjunta de 2001 sería una opción estratégica de primer orden para la política de seguridad de España.
\end{abstract}

Palabras clave: EEUU-España, política de seguridad, polaridad, percepciones, estabilidad estratégica, dilema de seguridad, Alianzas.

Title in English: "Spain and the US in a New Strategic Context"

\section{Abstract:}

The 2013 Spanish National Security Strategy sets a clear continuity with the 2011 Spanish Security Strategy regarding the treatment of the partnership and relations with the Unites States, showing a political consensus on a fundamental national policy for Spain. However, it tends to be more a political document and a declarative consensus than a security strategy with greater depth and width. In this sense, the National Security Strategy presents questionable conceptions and perceptions about the structure of the international system and the behavior of the great powers, which can create narratives, strategies and policies in a situation of decreasing capabilities. All this can lead to trigger a security dilemma. In this sense, alliances and strategic policies of Spain could move between its reinforcement (chain gangs) or abandonment (buckpassing), including more realistic strategic planning. A review of the Agreement on Defense Cooperation and the 2001 Joint Declaration Statement could be a first-class strategic option for the security policy of Spain.

Keywords: Unites States, Spain, Security Policy, Polarity, Perceptions, Strategic Stability, Security Dilemma, Alliances.

\section{Copyright $\odot$ UNISCI, 2014.}

Las opiniones expresadas en estos artículos son propias de sus autores, y no reflejan necesariamente la opinión de UNISCI. The views expressed in these articles are those of the authors, and do not necessarily reflect the views of UNISCI

\footnotetext{
${ }^{1}$ El Dr. David García Cantalapiedra es profesor de Relaciones Internacionales en la Facultad de Ciencias Políticas de la Universidad Complutense de Madrid, investigador senior de UNISCI y miembro del Foro Hispano-Argelino.

Dirección: Departamento de Estudios Internacionales, Facultad de Ciencias Políticas y Sociología, UCM, Campus de Somosaguas, 28223 Madrid, España.

E-mail: djgarcia@pdi.ucm.es. 


\section{EI Sistema Internacional y el marco estratégico global ${ }^{2}$}

Hay una serie de narrativas y posiciones en muchos análisis estratégicos contemporáneos (e incluso estrategias y políticas de seguridad) que asumen actualmente una clara situación de multipolaridad de la estructura del sistema internacional, la cual deviene de la Gran Recesión de 2007-8, implicando el declive relativo occidental y de la superpotencia unipolar, EEUU, con el orden internacional que ha promovido y mantenido desde el final de la Guerra Fría. Sin embargo, estos análisis se basan en una serie de factores, que, básicamente se refieren a aspectos relativos de las políticas de EEUU, a los problemas de algunos de sus aliados (en Europa y Asia), además de situaciones de ascenso de otras potencias producidas en los últimos 10-15 años, y cambios de alineamientos en el sistema internacional. A pesar de ello, ni unos ni otros factores, ni sobre todo ciertas expectativas o incluso las narrativas producidas a la luz de estas expectativas (más que de los factores reales) están produciendo ni las líneas de actuación ni los resultados esperados, al menos a corto o medio plazo. Algunos factores como la redistribución de capacidades o desconcentración de poder (para algunos, difusión de poder), han llevado a producir mayor percepción de anarquía e incertidumbre en el sistema internacional, además de una serie de realineamientos en una serie de potencias de diferente nivel, sean grandes, medias o pequeñas potencias (aunque en otros casos ha habido reafirmación de los alineamientos existentes).

En gran medida, ciertas visiones de multipolaridad, no polaridad, apolaridad, sistema policéntrico u otros conceptos (que favorecen ciertos discursos de deslegitimación), llevan a errores por una falta de análisis estratégico profundo y establecimiento de conclusiones "en lugares comunes". Así se produce confusión entre alineamientos y competición regional con multipolaridad, que pueden también existir en bipolaridad y unipolaridad; e incluso confusión de multipolaridad con incertidumbre. Realmente, en términos estructurales, esto es, el número de polos, selecciona y "socializa" a los actores hacia una determinada forma de conducta. Pero, sin embargo, se producen diferentes formas de conducta bajo multipolaridad: por ejemplo, chain gans o buckpassing. Se podría definir Chain-gang como una tendencia al mantenimiento de las alianzas ya que existe un convencimiento de que la propia seguridad está integrada a la de los aliados. Si se produce un conflicto, el apoyo a los aliados se da por hecho, ya que esa relación de seguridad, lleva a que una pérdida de la seguridad del aliado/s significa la propia ${ }^{3}$. En el segundo, el Buckpassing, significa el fracaso de los alineamientos para reequilibrar el sistema internacional porque hay actores que se aprovechan de los esfuerzos de los otros aliados por diferentes razones como reducir los costes o por mejorar su posición presente o futura. Estas conductas dependen de la estructura del sistema y de las percepciones sobre posición, capacidades y amenazas. La estructura del sistema (mayor o menor anarquía y distribución de capacidades-número de polos) impacta en las interacciones de los actores, o sea tienen un impacto sistémico de indeterminación. Así se produce una indeterminación en la conducta, por lo que es necesario utilizar las percepciones sobre los incentivos estratégicos según la visión de las diferentes capacidades de los actores. La propia estrategia nacional de seguridad española de 2013 señala:

\footnotetext{
${ }^{2}$ Agradezco a los comentarios del Pr. Marquina, la Pr. Natividad Fernández y otros colegas, junto con los debates sobre ciertos aspectos teóricos planteados en el panel Multipolaridad y conflictos periféricos, de las VI Jornadas sobre Seguridad celebradas en el Instituto Universitario Gutiérrez Mellado el 20 de mayo de 2014.

${ }^{3}$ Christensen, Thomas J. y Snyder, Jack: "Chain Gangs and Passed Bucks: Predicting Alliance Patterns in Multipolarity", International Organization, vol. 44, no. 2 (Primavera, 1990), pp. 137-168.
} 
"Un mundo como el actual, en el que países con intereses diversos, opuestos en ocasiones, buscan su prevalencia regional o global; un mundo multipolar, en definitiva, resulta más complejo y difícil de gestionar" ${ }^{\text {. }}$

La competición regional no se corresponde directamente con multipolaridad. De hecho, tanto en bipolaridad como en unipolaridad ha habido también competencia regional. ¿Y por qué se elige este término cuando incluso parte de la teoría de RRII (sobre todo la teoría crítica) lo considera insuficiente o no útil para describir la estructura del sistema internacional? Aun así, habría varias definiciones de multipolaridad que se podrían utilizar:

-Un sistema multipolar es un sistema en el que el poder se distribuye por lo menos entre 3 polos importantes de concentración de riqueza y/o capacidades militares, y capaz de bloquear o interrumpir grandes acuerdos políticos que amenacen sus principales intereses;

- La multipolaridad en la política internacional describe una distribución de poder en el que más de dos Estados-nación tienen cantidades casi iguales de influencia militar, cultural y económica.

-También un polo es un actor capaz de producir orden o generar desorden, o un polo se podría definir como un actor que tiene influencia en los resultados globales más allá de sus propias fronteras.

Desde este punto de vista, el poder militar, económico y normativo estaría distribuido entre EEUU, la UE, China, Japón, India y Rusia principalmente (Brasil, Indonesia, Turquía o Sudáfrica, a pesar de tener impacto regional, están muy lejos de estas capacidades e influencia aunque puedan poner "resistencia" a la superpotencia). Sin embargo, esta distribución no se concentra en términos totales entre tres o más, ni en cantidades casi iguales entre 3 o más; y de momento solo un actor tiene capacidad para influenciar globalmente. ¿Es la multipolaridad actualmente la situación estructural sistémica realmente? En el mejor de los casos, podríamos advertir una situación de incertidumbre donde existen tendencias en el sistema hacia una posible transición desde un sistema unipolar. Incluso realizando un análisis desde la teoría de los poderes estructurales de Susan Strage ${ }^{5}$ (aunque también argumentaba la inadecuación de las metodologías de análisis que estimaban el declive de EEUU en aquel momento), la transición en la estructura del sistema podría llevar a una bipolaridad, aunque dudosa desde el punto de vista militar, tecnológico y normativo, a pesar de los avances chinos en estos campos. Además, el propio declive europeo aumenta la diferencia con EEUU, luego la tendencia hacia una multipolaridad que pudiera incluir a la UE, Rusia, India y Japón junto a China y EEUU es dudosa cuando menos ${ }^{6}$. Tomemos por ejemplo, sin hablar de la clara

\footnotetext{
4 "Estrategia de Seguridad Nacional" (2013), p. 8.

${ }^{5}$ En este sentido véanse sus obras: Susan, Strange (1988): States and Markets, Nueva York, Pinter Publisher; Strange, Susan (1996): The Retreat of the State - The Diffusion of Power in the World Economy, Cambridge, Cambridge University Press; también, García Cantalapiedra, David (2001): "EEUU y la construcción de un Nuevo Orden Mundial: la Administración Bush, las Relaciones Transatlánticas y la Seguridad Europea (19891992)", Tesis Doctoral, Departamento de Derecho Internacional Público y Relaciones Internacionales, Facultad de CC. Políticas, Universidad Complutense de Madrid, pp. xxi-xxiv.

${ }^{6}$ Ver: Sharma, Ruchir: "Broken BRICs. Why the Rest Stopped Rising", Foreign Affairs, vol. 91, no 6 (Noviembre-diciembre 2012).
} 
unipolaridad militar norteamericana ${ }^{7}$, un factor en el campo económico como es la acumulación de reservas internacionales por parte de los BRIC, que a menudo se considera un barómetro clave del creciente poder de las economías de las potencias emergentes. Por extraño que parezca, esto sería un claro ejemplo de cómo el poder estructural funciona, porque la acumulación de reservas en moneda extranjera en dólares estadounidenses confirma tres características importantes del poder estructural norteamericano: uno, Estados Unidos todavía tiene la confianza del mundo como el proveedor preeminente de la liquidez mundial; dos, que en este momento no hay rivales serios para acumular y utilizar dólares estadounidenses como moneda de reserva internacional, incluso si esos que acumulan dichas reservas se quejan de esta injusticia; y tres, mientras que los países BRIC y otros tienen que ganarse su liquidez (que son los que representan dichas reservas), Estados Unidos puede simplemente crear su liquidez: es difícil pensar en un mejor indicador del poder estructural, a pesar de los intentos de que el euro, o recientemente el remimbi pueda llegar a serlo. Lo que es especialmente importante en el momento actual, sin embargo, es que en la agenda global de toma de decisiones económicas no parece que haya cedido poder sustancial a las economías de mercados emergentes ${ }^{8}$, a pesar de ejemplo de la acumulación de enormes reservas de dólares o el cambio en los derechos de voto en el FMI (que puede promover un mayor control de capitales $)^{9}$.

Incluso teniendo en cuenta la profunda discusión sobre las políticas de EEUU tanto desde un punto de vista externo como incluso el debate interno dentro del propio país, sería imprudente realizar un análisis de la estructura del sistema internacional y del marco estratégico global desde este enfoque, ya que las conclusiones se deberían de establecer a partir de la estructura del sistema y, por otro lado, desde los mecanismos de legitimación/ deslegitimación del orden internacional. Los cambios en las políticas, realineamientos e incertidumbre producidos por la Gran Recesión, el abandono de las políticas en Iraq y Afganistán, el ascenso de China y otras potencias, y el proceso de desgaste del liderazgo norteamericano durante la Administración $\mathrm{Bush}^{10}$ (y por ende, del orden internacional promovido y protegido por EEUU) ha ido acompañado de una campaña de deslegitimación de dicho orden. Así, la desconcentración de poder, junto con ese proceso de deslegitimación ha ofrecido una narrativa de multipolaridad. Sin embargo, esto no sería sino una fase en un

\footnotetext{
${ }^{7}$ Posen, Barry (2003): "Command of the Commons: The Military Foundation of U.S. Hegemony", International Security, vol. 28, n 1 (Verano 2003), pp. 5-46.

${ }^{8}$ Aunque hay que decir que hay señales y conductas por parte de las potencias emergentes (en lo posible) encaminadas a "ignorar" esas instituciones económicas internacionales que no tienen en cuenta esos cambios en la redistribución de poder económico.

${ }^{9}$ Germain, Randall: "The Political Economy of Global Transformation: Susan Strange, E.H. Carr and the Dynamics of Structural Change", en Workshop "A Retrospective on the Work of Susan Strange" (Princeton University, 10-11 January 2014), en http://www.princeton.edu/ pcglobal/conferences/strange14/germain.pdf.

${ }^{10}$ A pesar de la retórica de la hegemonía o de la hyperpuissance, se debería hablar de primacía, aunque pudiera caracterizarse de "imperial". En este sentido, ver: Lieber, Robert J. (2012): Power and Willpower in the American Future: Why the United States Is Not Destined to Decline, Nueva York, Cambridge University Press; también del mismo autor: (2007): The American Era: Power and Strategy for the 21st Century. Cambridge University Press; también: García Cantalapiedra, David: "Peace Through Primacy. La Administración Bush, La política exterior de EE.UU y las bases de una Primacía Imperial”, UNISCI Discussion Papers, n 4 (Enero 2004), en

http://pendientedemigracion.ucm.es/info/unisci/revistas/Bush.pdf; Desde un punto de vista teórico, el debate sobre la unipolaridad es muy rico y amplio. En este sentido, es quizá Robert Jervis el autor que establece mejor las características de un sistema unipolar, que no es ni hegemonía ni imperio. Sin embargo, también duda de la viabilidad de la creación de un concepto general de unipolaridad cuando realmente se podría estimar que sólo hay un caso empírico histórico para poder establecer ese concepto, que es la experiencia derivada del caso de EEUU. Ver: Jervis, Robert: “Unipolarity: A Structural Perspective”, World Politics, vol. 61, no 1 (2008).
} 
proceso hacia el fin de esa unipolaridad, pero que no se habría producido aún, que no se sabe el tiempo que llevará, y que habrá que comprobar hasta qué punto deslegitima y realmente crea un sistema multipolar ${ }^{11}$.

Paradójicamente, el propio EEUU ha llevado a cabo toda una serie de revisiones estratégicas, políticas e incluso narrativas que favorecen esa percepción de declive y situación de multipolaridad, incluso reconociendo la existencia de otros centros de poder, como por ejemplo, en su Estrategia de Seguridad Nacional de $2010^{12}$. Sin embargo, esta visión se empieza a conformar ya al final de la Administración Bush, con la revisión de la política de EEUU hacia Asia, en el informe del CSIS (Center for Strategic and International Studies) de febrero de 2007, dirigido por Richard Armitage, y Joseph Nye, "The U.S.-Japan Alliance: Getting Asia Right through 2020"13. Sin embargo, no es la primera vez que EEUU lleva a cabo ese tipo de políticas, incluso considerando la existencia de una paridad estratégica o incluso una situación de tripolaridad o pentapolaridad, tal como llevo a cabo la Administración Nixon con la política de distensión durante los años $70^{14}$ que dio lugar a las teorías "declinistas"15. Efectivamente, el reforzamiento soviético, la guerra de Vietnam, las cargas del proyecto de Gran Sociedad y el fin del modelo de crecimiento económico producido bajo el paraguas del sistema Bretton Woods desde los años 50, amén de la crisis del petróleo durante esa década y el fracaso de la distensión, llevó a cambios estratégicos a EEUU de tal magnitud, que al final de la década de los 70 se llegó a pensar en la derrota en la Guerra Fría y al declive de EEUU. Aunque desde un punto de vista económico, la crisis hoy es más profunda, y existe un declive relativo en los principales aliados de EEUU también (véase sobre todo Europa), y un apreciable desplazamiento hacia Asia del centro de gravedad internacional, los ajustes políticos tanto exteriores como interiores de EEUU pueden entrar en el campo de la discusión, pero habría que analizar su impacto a largo plazo en el contexto global, no solo desde un punto de vista de corto o incluso medio plazo. A pesar de ello, habría que analizar el proceso de desconcentración y deslegitimación que se está produciendo, sobre todo desde el punto de vista de la "legitimación" del revisionismo de las potencias emergentes como China, Rusia o incluso India y Brasil. Así, desde un punto de vista político-estratégico hay toda una serie de posturas entre las grandes potencias que reafirman esta situación de multipolaridad como la propia UE, China, Rusia, India, Brasil o Francia; en el campo académico, en posturas tan dispares como el realismo estructural y el constructivismo. En particular, el realismo estructural (autores como Kenneth Waltz, Stephen Walt o John Mearshimer) en sus diferentes variantes establece este proceso de reequilibrio en el sistema internacional. Sin embargo, aunque el proceso es posible, podemos decir que en diferentes

\footnotetext{
${ }^{11}$ Randall, Schweller y Pu, Xiaoyu: "After Unipolarity: China's Visions of International Order in an Era of U.S. Decline", International Security, vol. 36, nº 1 (Verano 2011), pp. 41-72.

12 Ver por ejemplo: President Barak Obama: "National Security Strategy 2010", The White House, Washington DC. (2010), pp. 3, 7, 11,41, 43, 44, en

http://www.whitehouse.gov/sites/default/files/rss_viewer/national_security strategy.pdf.

${ }^{13}$ Ver: García Cantalapiedra, David: "El despliegue estratégico de EEUU, la República Popular de China y la seguridad en Asia 2001-2010", UNISCI Discussion Papers, n' 24 (2010), en http://revistas.ucm.es/index.php/UNIS/article/viewFile/UNIS1010330083A/26926.

${ }^{14}$ García Cantalapiedra, David: "The Obama Doctrine, the Irak Syndrome and US Foreign Policy: toward a NeoNixonian Policy?", 2012 ISA-BISA International Conference, University of Edimburg, pp. $20-22$ (Junio de 2012).

${ }^{15}$ Entre ellas, las obras más famosas son Kennedy, Paul (1987): The Rise and Fall of the Great Powers: Economic Change and Military Conflict from 1500 to 2000. Nueva York, Random House,; Robert, Keohane (1984): After Hegemony: Co-operation and Discord in the World Political Economy, Princeton, Princeton University Press.
} 
áreas no se ha producido aún, y que puede llevar a otro tipo de resultados no queridos o no esperados ${ }^{16}$.

\section{2- "Nuestro" Entorno Estratégico v la postura estratégica de EEUU}

Esta concepción general sobre el sistema internacional y el marco estratégico global podría ser peligrosa tanto para la UE como para España ya que da lugar (en una situación de declive relativo -o pronunciado- de la UE/España), a análisis producidos por cierto tipo de narrativas y análisis sesgados en función de las opciones estratégicas de las que se disponen, sobre todo ante la impracticabilidad de ciertos alineamientos erróneos o ilusorios, e incluso consideraciones de autonomía irrelevante. Ciertamente, estas posiciones provienen de una situación muy determinada en la política interna de los Estados miembros y de la UE en general, y de una crisis social y económica, pero también de valores y objetivos, sin precedente en Europa desde la Gran Depresión y la $2^{\text {a }}$ Guerra Mundial. Para la UE y para España es vital, al punto de poder producir la irrelevancia estratégica, un análisis del sistema internacional, partiendo de un entendimiento de la estructura del sistema como uno de los factores básicos a la hora de desarrollar las políticas y estrategias de ambos. El otro factor fundamental sería la plasmación en políticas internas y la toma de decisiones doméstica. Dado lo limitado del espacio, este último factor no será analizado en profundidad, pero no se podría realizar un análisis válido sin tener en cuenta los factores internos en esa construcción de políticas. Sin embargo el análisis será principalmente del factor estructural y sistémico y cómo este podría afectar a la construcción de una política y estrategia de la UE y de España, sobre todo teniendo en cuenta algunos escenarios y estrategias como el llamado vecindario estratégico para la UE, o el espacio euro-atlántico para la ESN 2013. Aunque, realmente, desde este punto de vista, en el ESN 2013 la idea del espacio euro-atlántico no parece que estime que en esta área haya una situación multipolar.

\subsection{Percepciones $\mathrm{v}$ conceptos. Incertidumbre, indeterminación, interdependencia: ¿qué "Multipolaridad" entonces?}

La ESN 2013 establece una situación de incertidumbre en el sistema internacional: "Asimismo, la situación de incertidumbre aumenta en tanto que las tendencias que van definiendo el mundo emergente no apuntan todavía contornos definidos para la nueva comunidad internacional". Este planteamiento produce una serie de cuestiones y acarrea una serie de dudas:

-Si hay mayor incertidumbre, ¿esto impacta en la estructura del sistema, en los actores o en sus interacciones?

-Si las tendencias no crean contornos definidos, ¿cómo calificar el sistema de multipolar?

¿QQué es para los autores multipolaridad?

-Ausencia de los actores no estatales en el análisis: por ejemplo, de las 150 primeras economías del mundo, 87 son MNC. ¿Y cuáles son "brazos armados” de los Estados?

\footnotetext{
${ }^{16}$ Desde este punto de vista, ver: Jervis, Robert (1998): System Effects, Princeton, Princeton University Press,
} 
Sin embargo, la incertidumbre no tendría que significar linealmente multipolaridad.

Incertidumbre en general se refiere a cómo enfrentarse a la falta de información sobre las intenciones de los otros actores y al poder de los actores con los que interactúan ${ }^{17}$, esto es, a la incertidumbre estratégica; generalmente lo harán acumulando capacidades o a través de alianzas (cooperación).

La incertidumbre existe también en unipolaridad y en bipolaridad, ya que se refiere a un parámetro que se alimenta de un factor estructural del sistema, que es básicamente la mayor o menor anarquía, y las percepciones de los actores sobre el sistema, en términos de su posición en éste. Es la conjunción de estos factores la que llevará a la indeterminación de la conducta, como dirían también las teorías constructivistas ${ }^{18}$. Esto puede llevar a realineamientos regionales (y aunque parezca que exista actualmente, no hay un realineamiento global claro aún) que incluyan opciones clásicas de reequilibrio (balancing; al menos external balancing, aunque si internal balancing por parte de algunos actores) con intentos más allá de reequilibrio suave (soft balancing) ${ }^{19}$. La Multipolaridad como factor estructural que impacta en los actores, no como descripción de la conducta de los actores del sistema internacional, acrecentaría la indeterminación de la conducta y las opciones y elecciones estratégicas, al incluir más actores, cálculos sobre los incentivos estratégicos y percepciones ${ }^{20}$. En este sentido, habría una serie de efectos sistémicos como interdependencia entre los cursos de acción elegidos y cómo afectan las acciones de los otros actores, y cómo acciones a nivel sistémico se producen por factores a niveles domésticos o incluso más bajos. El gran problema es que estos efectos que estaban o no previstos van a tener efectos sistémicos.

También es discutible la interpretación de los efectos de la interdependencia, ya que se atribuye linealmente una reducción de una probabilidad, la de conflictos clásicos entre Estados. Se supone que se refiere a guerras "convencionales clásicas" entre Estados: "En la actualidad la interdependencia global ha disminuido la probabilidad de confrontaciones clásicas entre Estados, pero los conflictos armados siguen representando una amenaza capital para la seguridad". Realmente el rasgo definitorio de la interdependencia es la incertidumbre: hay demasiados objetivos, todos compitiendo para llamar la atención; no existe un acuerdo sobre la mejor manera para alcanzarlos ${ }^{21}$; la comprensión de las causas está sujeta a disputa ideológica, no a un consenso; lo que es una causa para un actor es un efecto a otro". La interdependencia crea no sólo el dilema estratégico, esto es, qué respuestas de los Estados dependen de las decisiones de los demás. La interdependencia también significa que las

\footnotetext{
${ }^{17}$ Por ejemplo, ver: Mearsheimer, John J. (2001): The Tragedy of Great Power Politics, Nueva York, Norton; También, Mearsheimer, John: "The False Promise of International Institutions". International Security, vol. 19, $\mathrm{n}^{\circ} 3$ (Invierno 1994/1995), pp. 5-49.

${ }^{18}$ Para una revision del significado de la incertidumbre en las diferentes teorías de relaciones internacionales, ver: Rathbun, B. C.: "Uncertain about Uncertainty: Understanding the Multiple Meanings of a Crucial Concept in International Relations Theory", International Studies Quarterly, vol. 51, no 3 (2007), pp. 533-557.

${ }^{19}$ Ver: Brooks, Stephen y Wohlforth, William C.: "Hard Times for Soft Balancing", International Security, vol. 30, no 1 (Verano 2005); Pape, Robert: "Soft Balancing against the United States", International Security, vol. 30, $\mathrm{n}^{\circ} 1$ (Verano 2005); Paul, T.V: "Soft Balancing in the Age of U.S. Primacy", International Security, vol. 30, $\mathrm{n}^{\circ}$ 1. (Verano 2005); "In some cases, the states are not powerful enough to face directly the power of the adversary and use a non-violent diplomatic insurgency that calls soft balancing, a term coined recently for "organized diplomatic harassment of the United States", that like any other balancing, must be "linked causally to the systemic concentration of power in the U.S." and must be motivated by the concern that "the concentration of power in the United States" could become "a direct security threat", en Brooks and Wohlforth, op. cit., pp. 7879 y Paul, op. cit., p. 47.

${ }^{20}$ Christensen y Snyder, op. cit., p.14.

${ }^{21}$ Ver: Haas, Ernst B.: "Why Collaborate?: Issue-Linkage and International Regimes", World Politics, vol. 32, no 3 (1980), pp. 357-405.
} 
cuestiones con que los Estados deben lidiar están relacionados entre sí e implican un número creciente de actores, haciéndolos mucho más difícil de manejar. El esfuerzo es menos sobre cómo conseguir lo que uno quiere en un entorno estratégico de negociación, y más en cómo los Estados han agregado un número cada vez mayor de objetivos que inevitablemente debe equilibrarse uno contra el otro y llevados a cabo con otros ${ }^{22}$.

Aunque el ratio de conflictos internacionales (sobre todo guerra inter-estados "clásicas") se ha ido reduciendo desde el final de la Guerra Fría, esta misma interdependencia podría provocar más fácilmente conflictos entre Estados, por ejemplo, espacios de alta interdependencia con baja institucionalización como es Asia, o casos como la Europa prePrimera Guerra Mundial ${ }^{23}$. Se atribuye a la interdependencia efectos positivos altamente discutibles y no se nombra el efecto de la existencia de armas nucleares, a la superioridad militar convencional norteamericana, o a la existencia de la OTAN, como mecanismos de mantenimiento de la estabilidad. De la misma forma, se le atribuye a la interdependencia global la paz entre las grandes potencias, sin embargo se podría estar confundiendo globalización con interdependencia, y, además, las dinámicas de globalización son asimétricas: las hay en algunas áreas y en otras no, aunque hay desafíos o dinámicas globales. Pero la paz, o mejor dicho la estabilidad, podría ser un efecto de la unipolaridad. Y aunque la unipolaridad no tiene por qué determinar la paz global, sí la estabilidad: no hay conflictos "clásicos" entre las grandes potencias o con la superpotencia, aunque esto no inhiba al sistema internacional de conflictos entre la superpotencia y otras potencias, o entre potencias medianas, o entre grandes potencias y/o medianas y pequeñas potencias.

Así, para realizar un correcto análisis de las opciones de alianzas y la conducta de los Estados en términos de políticas, hay que tener claro tanto la polaridad del sistema, como las percepciones de los incentivos estratégicos y la creación de dilemas de seguridad; esto nos permitirá observar la conducta de la política exterior de los actores teniendo en cuenta ese impacto estructural. Los errores de percepción e identificación de la estructura del sistema pueden llevar a errores estratégicos o efectos no queridos. Por ejemplo, errores al considerar escenarios multipolares o bipolares cuando son tripolares ${ }^{24}$, o percepciones erróneas sobre la ventaja de la ofensa o la defensa en la primera y segunda guerras mundiales ${ }^{25}$. El cambio en la distribución de capacidades puede llevar a un aumento de la percepción de anarquía (impacto estructural), que junto con los cambios en la política de EEUU (en cuanto a prioridades, no como abandono de intereses y presencia global) crea una percepción de multipolaridad. Sin embargo, habría que esperar a la concreción en términos de distribución de poder y en realineamientos regionales, alianzas de reequilibrio (rebalancing) o claros aspirantes regionales/globales. En este sentido, el desplazamiento hacia Asia del centro de los asuntos mundiales implica realineamientos regionales. Sin embargo, a pesar de la expansión de los intereses chinos, los cambios en las políticas de Japón, Corea y India, el reforzamiento de sus alianzas con EEUU, amén de la producida con ANZUS y con varios estados de la ASEAN, no ha producido una ruptura del orden asiático, manteniéndose la estructura de alianzas que creó

\footnotetext{
${ }^{22}$ Haas, Peter M.: "Introduction: Epistemic Communities and International Policy Coordination”. International Organization, vol. 46, n (1992), pp. 1-35.

${ }^{23}$ Snyder, Jack: "Five lessons for China about 'peaceful rise' from 1914", Washington Post, 28 de abril del 2014, en http://www.washingtonpost.com/blogs/monkey-cage/wp/2014/04/28/five-lessons-for-china-about-peacefulrise-from-1914/.

${ }^{24}$ Randall, Schweller (1998): Deadly Imbalances: Tripolarity and Hitler's Strategy of World Conquest, Nueva York, Columbia University Press; Randall, Schweller: "Tripolarity and the Second World War", International Studies Quarterly, vol. 37, nº 1 (Marzo 1997).

${ }^{25}$ Christensen, Thomas J.: "Perceptions and alliances in Europe, 1865-1940", International Organization, vol. 51, no 1 (1997), pp. 65-97; Christensen, Thomas J. y Snyder, Jack: “Chain Gangs and Passed Bucks: Predicting Alliance Patterns in Multipolarity”. International Organization, vol. 44, no. 2 (Primavera, 1990), pp. 137-168.
} 
EEUU como arquitectura de seguridad, a pesar de que ha habido cambios en la conducta de la República Popular China, iniciativas como el reforzamiento de la Organización de Cooperación de Shanghai o la iniciativa de la East Asia Summit. De hecho se ha producido una reafirmación de la red de alianzas que tiene EEUU, con respuestas firmes a los movimientos chinos. Es más, no se observa una retirada de EEUU. Su política del PivotRebalance es la culminación de la política ya comenzada en la Administración Bush en función de su 2004 Global Posture Review y los Informes Nye/Armitage de 2000 y $2007^{26}$. Hay una contestación a la política norteamericana, pero ese aspecto no significaría la ruptura de esa situación de unipolaridad, ya que ésta no es el resultado de las políticas de EEUU, sino de la estructura del sistema ${ }^{27}$. Sin embargo, ese desplazamiento, debido al declive relativo occidental (mayor europeo que norteamericano) y el cambio de prioridades estratégicas de EEUU, sí produce un cambio en el statu quo global de la posición relativa de Europa. La desconcentración de poder, las dinámicas de interdependencia y la interconexión cibernética crean un entorno de seguridad potencial no favorable si se está en una situación de vulnerabilidad o reducción de capacidades para enfrentarse a un sistema internacional altamente dinámico en sus procesos ${ }^{28}$. Esta situación debería, por ejemplo, llevar a la creación de un concepto de seguridad complejo, nuevo y creíble. Sin embargo, en el caso europeo y español, no parece que haya una concepción claramente definida, viable y operativa.

\subsection{El problema de la seguridad: España. EEUU v las relaciones transatlánticas}

El primer problema para el establecimiento de una estrategia de seguridad y defensa española es que no hay una definición de intereses vitales y de intereses estratégicos de España. La única definición que se puede considerar así es la que hace la estrategia al definir Seguridad Nacional: "proteger la libertad y el bienestar de sus ciudadanos, a garantizar la defensa de España y sus principios y valores constitucionales, así como a contribuir junto a nuestros socios y aliados a la seguridad internacional en el cumplimiento de los compromisos asumidos" ${ }^{, 29}$. Se puede asumir que el orden de su enunciación es la prioridad o jerarquía de dichos intereses. De aquí no podríamos extraer una valoración real del significado de la relación con EEUU, y posteriormente la estrategia realiza, en los siguientes apartados, una visión instrumental, que identifica los intereses de España en función del valor de la relación con EEUU, no al contrario; estableciendo los intereses de España y diciendo por qué es importante la relación con EEUU para la defensa de esos intereses. Aun así hay referencias que especifican intereses de España: el espacio euro-atlántico (aunque no está definido en la estrategia) donde se insiste en que la relación con EEUU es vital para defenderlos (también lo es la OTAN según el documento). También parece que se podría descubrir un interés de España en mantener un bandwagoning hacia EEUU en algunos temas (sobre todo en Iberoamérica y para evitar competición entre ambos) ante el declive de la posición y las capacidades españolas ${ }^{30}$. A la vez, hay una alta valoración global como socio y aliado sólido y fiable (aunque aparece mejor definido en la estrategia de seguridad española de 2011) en estos

\footnotetext{
${ }^{26}$ Ver: García Cantalapiedra, David: "El despliegue estratégico de EEUU, la República Popular de China y la seguridad en Asia 2001-2010", UNISCI Discussion Papers, no 24 (2010), en http://revistas.ucm.es/index.php/UNIS/article/viewFile/UNIS1010330083A/26926.

${ }^{27}$ En cuanto a este debate véase por ejemplo Nuno P., Monteiro: "Unrest Assured. Why Unipolarity Is Not Peaceful", International Security, vol. 36, no 3 (Invierno 2011/12), pp. 9-40; Jervis, Robert: "Unipolarity: A Structural Perspective", World Politics, vol. 61, no 1 (Enero 2009), pp. 188-213; para otras opiniones sobre la actual situación, ver Schweller y $\mathrm{Pu}$, op. cit.

${ }^{28}$ Ver por ejemplo: Rowe, David M.: "World Economic Expansion and National Security in Pre-World War I Europe", International Organization, vol. 53, no 2 (Primavera, 1999), pp. 195-23.

29 "Estrategia de Seguridad Nacional" (2013).

${ }^{30}$ Ibid., pp. 15-17.
} 
temas vitales: la seguridad internacional, el espacio euro-atlántico, y el caso de la no proliferación, en referencia a la OTAN.

La Estrategia de Seguridad Nacional de 2013 apela a un concepto amplio de seguridad, multidisciplinar y multilateral, con una serie de factores que le afectan pero que no quedan claros:

- "la evolución constante de los centros de poder, con nuevas potencias en ascenso," (¿se refiere a multipolaridad, pluricentrismo u otro sistema?)

- la consolidación de nuevos actores internacionales (¿cuáles?)

- la mayor capacidad de influencia adquirida por parte de los individuos (¿gracias a las tecnologías de la información, al terrorismo?),

- los cambios demográficos,

- la mayor competencia por los recursos energéticos, alimenticios y económicos,

- así como el papel de las tecnologías en la sociedad del conocimiento

- o la mayor interdependencia económica, política y jurídica (¿Es positiva o negativa?).

Sorprende la confusión entre factores, desafíos, dinámicas, y actores. Parece que se quiere acudir a una definición de seguridad comprehensiva junto con un enfoque integral (comprehensive approach), pero no queda claro: "la respuesta a los riesgos y amenazas que comprometen la seguridad en nuestros días precisa de cooperación tanto en el plano nacional como en el multilateral. Las respuestas unilaterales y aisladas no son eficaces, por su carácter incompleto y parcial, frente a unos retos que exigen un enfoque multidisciplinar y una acción conjunta. Solo esta perspectiva abarca todos los aspectos potencial o realmente afectados"31. En este sentido, la postura de la ESN 2013 es que las organizaciones como OTAN o UE serán el mecanismo para la defensa solo de intereses y valores compartidos, sin hacer referencia a que en última instancia son mecanismos de defensa colectiva y defensa mutua (artículos $\mathrm{V}$ en OTAN y 42.7 TUE en el Tratado de Lisboa), no solo para capacidad expedicionaria: "Hacer frente a los conflictos armados que se puedan producir como consecuencia tanto de la defensa de los intereses o valores exclusivamente nacionales -en los que se intervendría de manera individual-, como de la defensa de intereses y valores compartidos en virtud de nuestra pertenencia a organizaciones internacionales tales como la ONU, la OTAN o la UE", en los que se intervendría conforme a sus tratados constitutivos junto con otros aliados o socios.

-Se produce una confusión entre unilateralidad y enfoque multidisciplinar: por ejemplo, puede haber acciones unilaterales multidisciplinares, o multilaterales solo militares (unidisciplinar). Además se contradice con párrafos (p.12) en cuanto a que "Finalmente, es una prioridad estratégica mantener la debida preparación y capacidad de nuestro país para abordar aquellas amenazas a las que tenga que hacer frente de forma autónoma". O en la página 24, "Por una parte, se debe mantener una capacidad defensiva propia, creíble y efectiva, dada la situación geográfica de España".

\footnotetext{
${ }^{31}$ Ibid., p. 6.
} 
- En la definición de Política de Seguridad sólo se habla de desafíos, y nada sobre amenazas o riesgos. Es sorprendente que tampoco se hace ninguna referencia a los conflictos híbridos y su impacto en los problemas de seguridad presentes y del futuro ${ }^{32}$. También es discutible la identificación de amenazas, riesgos, desafíos y su prioridad global y sobre todo cuáles son prioritarias para España. Parece que además existe esta falta de identificación y priorización debido a la necesidad de España de mantenerse en estructuras multilaterales para dar respuesta a ciertas amenazas y desafíos a los intereses vitales que no pueden ser afrontados individualmente, por lo que se "adoptan" visiones no necesariamente idóneas para España. Esto, además, no hace que los alineamientos y alianzas que establece España den respuesta a esos intereses vitales de España: por ejemplo, el Norte de África, no cubierto por OTAN y con pocas opciones de solidaridad por parte de UE a pesar del Tratado de Lisboa. Eso hace que haya una tendencia al reforzamiento de la alianza con EEUU, aunque no existe tampoco un mecanismo automático en este caso con tal escenario.

- A pesar de que hay una enumeración de riesgos y amenazas (aunque no se clarifica cual está en cada categoría), hay una ausencia de mención y análisis de las amenazas militares producidas en el ciberespacio y su conexión con otras dinámicas como la disuasión nuclear, proliferación de armas de destrucción masiva, BMD, armas convencionales avanzadas (por ejemplo Prompt Global Strike) ${ }^{33}$, la robotización del campo de batalla y la militarización del espacio, que está produciendo un cambio estructural en la estabilidad estratégica.

Sin embargo lo más sorprendente desde el punto de vista de la seguridad y de la relación con EEUU, es el absoluto silencio de la ESN 2013 acerca del Convenio de Cooperación para la Defensa de 1988 entre España y EEUU ${ }^{34}$, amén de la Declaración Conjunta de 2001, en términos del papel que juega tanto su contenido, como la estructura institucional creada para su funcionamiento (como el Comité de Defensa Bilateral de Alto Nivel creado por el Protocolo de Enmienda de 2002), como cuál sería realmente el papel de la alianza EspañaEEUU en términos de seguridad de acuerdo a los objetivos de la ESN 2013: cómo encaja el artículo 1.1 del Convenio con los objetivos de la estrategia y con el papel de EEUU en ella: "Ambas partes reafirman que el mantenimiento de la seguridad y plena integridad territorial respectivas, y la continuación de una fuerte relación defensiva entre ellas, sirven al interés común, contribuyen a la defensa de Occidente, y ayudan a la conservación y desarrollo de su capacidad individual y colectiva para resistir un ataque armado"35. En este sentido, el único

\footnotetext{
${ }^{32}$ Ibid., p. 8: Actualmente existe un debate teórico sobre el concepto; ver por ejemplo: Mattis, J. y Hoffman, F.: "Future Warfare: The Rise of Hybrid Wars", USNI, Proceedings, vol. 132, n 11, parte 1,233 (November 2005); Hoffman, Frank: "Conflict in the 21st Century: The Rise of Hybrid Wars", Potomac Institute for Policy Studies (2007); Hoffman, F: "Hybrid Warfare and Challenges", JFQ, vol. 52, 1st quarter 2009; Murray, W. y Mansoor, Peter R. (2012): Hybrid Warfare. Fighting Complex Opponents from the Ancient World to the Present, Cambridge, Cambridge University Press.

${ }^{33}$ Woolf. A.: "Conventional Prompt Global Strike and Long-Range Ballistic Missiles: Background and Issue", Congressional Research Service, (5 de mayo del 2014), en http://www.fas.org/sgp/crs/nuke/R41464.pdf.

${ }^{34}$ Realmente la modificación a través del primer protocolo de enmienda de 2002 (con 54 artículos nuevos) dio un significado nuevo a la alianza entre EEUU y España, en el marco de la Declaración Conjunta de 2001; en este sentido, ver: García Cantalapiedra, David: "Spanish Foreign Policy, the Unites States and Soft Bandwagoning", en García, D. y Pacheco, R (2014): Contemporary Spanish Foreign Policy, Nueva York, Routledge.

${ }^{35}$ Ver Ramírez, E.: "Presente y Futuro del Convenio para la Cooperación para la Defensa entre España y EEUU", UNISCI Discussion Papers, no 3 (Octubre 2003), en

http://revistas.ucm.es/index.php/UNIS/article/viewFile/UNIS0303330005A/28300.
} 
aspecto actual referido al Convenio sería el segundo protocolo de enmienda de $2012^{36}$, que establece la modificación del acuerdo para permitir el estacionamiento en la base naval de Rota de los cuatro buques AEGIS para contribuir al sistema de defensa anti-misiles balísticos de la Alianza Atlántica. Sin embargo, la ESN 2013 tampoco dice nada en su apartado relativo a las armas de destrucción masiva o sistemas de lanzamiento, aunque sí hace referencia al apoyo al despliegue de un sistema "autónomo" de defensa antimisiles. ${ }^{37}$.

\section{3. "Nuestro" Entorno Estratégico. España. EEUU y el espacio euro- atlántico}

La Unión Europea, y España como Estado miembro, ha intentado, en un camino difícil y tortuoso, la definición de sí misma y de su papel en un sistema internacional en transformación que difícilmente responderá al marco internacional integrado por los países occidentales desde el fin de la Segunda Guerra Mundial y después de la final de la Guerra Fría. Esto también ha tenido un impacto profundo en España ya que la progresiva europeización de las políticas españolas, en este caso, estratégica y de seguridad, condiciona también, por su dependencia, las opciones y elecciones de España. En este sentido, es fundamental comprender la postura estratégica y la visión de seguridad de la UE para comprender en qué sentido puede esto condicionar las opciones españolas. Esta postura refleja aún algunos postulados que son muy discutibles, incluso algunos están anticuados porque siguen insistiendo en ciertas posiciones sobre ventajas de poder normativo, o no responden a una lectura correcta de la dinámica del sistema internacional. Desde este punto de vista, la estrategia de seguridad europea de 2003, los cambios realizados en 2008, o las conclusiones del Consejo Europeo de diciembre de $2013^{38}$, siguen sin reconocer realidades fundamentales del sistema internacional y mantienen una postura que afecta y afectará la seguridad europea. Solo el proyecto de Estrategia Global Europea, a través del informe "Towards a European Global Strategy. Securing European Influence in a changing World" 39 , iniciativa de una veintena de think tanks europeos, trataba de establecer una nueva aproximación estratégica para la UE, intentando dejar atrás algunos planteamientos y estableciendo algunos nuevos, pero tampoco de forma concluyente. Por ejemplo, parece que la percepción de un sistema multipolar que se tiene se basa más en la creencia en el declive de los Estados Unidos, que en un declive de la UE y la reducción de su papel; y el peso del "Club de la Unipolaridad" del cual es parte. Además también agregó la idea de crear una "identidad " propia, por oposición a EE.UU ${ }^{40}$. La Unión Europea aceptaría una redistribución de poder, esto es, una situación de multipolaridad, al asumir la reducción de la posición de EE.UU, pero no de la UE, dentro de la dinámica de ascenso de otras grandes potencias. Esta reducción en el poder de EE.UU. con respecto a estos "nuevos " poderes y para la UE, llevarían a establecer necesariamente un sistema multipolar, donde la distribución de poder relativo dejaría a la UE en una "mejor

\footnotetext{
${ }^{36}$ Segundo Protocolo de enmienda del Convenio de Cooperación para la defensa entre el Reino de España y los Estados Unidos de América, de 1 de diciembre de 1988, revisado, hecho en Bruselas el 10 de octubre de 2012, en http://www.ieee.es/Galerias/fichero/Varios/BOE_ConvenioCooperacion_Espana-EEUU_jun2013.pdf.

37 "Estrategia de Seguridad Nacional" (2013), pp. 31 y 46.

${ }^{38}$ Consejo Europeo: "Conclusiones del Consejo Europeo sobre la Política Común de Seguridad y Defensa" (19 de diciembre del 2014), en http://www.consilium.europa.eu/uedocs/cms data/docs/pressdata/en/ec/140214.pdf.

39 EGS Project: "Towards a European Global Strategy. Securing European Influence in a changing World" (2013), en http://www.euglobalstrategy.eu/nyheter/opinions/towards-a-european-global-strategy-report-release

${ }^{40}$ García Cantalapiedra, David: "Towards a European Global Strategy: Securing European Influence in a Changing World", EUSA Review (Primavera 2013), pp. 15-17, en

http://www.eustudies.org/files/eusa_review/Spring13.pdf.
} 
posición relativa " con respecto EE.UU., reforzada por la reducción de la posición relativa de EE.UU. a nivel mundial con respecto a las potencias emergentes. Sin embargo esto es una mera ilusión. La posición de la UE en términos de poder relativo también se ha reducido, y luego la posición relativa de la UE es peor en cualquiera de las categorías y escenarios, con respecto a EE.UU. y en relación con las potencias emergentes. La pregunta es por qué la ESN 2013 (y también políticamente a la UE, tal como reflejan diferentes documentos como la EGS 2013 o las conclusiones del Consejo Europeo sobre la PCSD en diciembre de 2013) acepta esta idea. En el caso de EEUU es discutible, a pesar de cierto declive relativo, pero es casi la aceptación de un fatum fatale por parte la UE. Parece que la Unión Europea es más propensa a creer en un sistema multipolar porque esto hace que mantenga un papel como uno de los polos entre las grandes potencias. Otra definición del sistema internacional sería en términos menos favorables, como el papel llevado a cabo durante la bipolaridad, o más marginal durante la Pos-Guerra Fría. Esta parece ser una tendencia arraigada en la creencia de que la estructura ideacional del sistema, de acuerdo a visiones y teorías constructivistas del sistema internacional, y el "reconocimiento" por otras grandes potencias, creará realmente esta posición para la $\mathrm{UE}^{41}$.

No obstante el EGS 2013 (como la ESN 2013) defiende la idea de una tendencia en el sistema internacional hacia la multipolaridad (en diferentes momentos y con diferente contenido), pero también se prevén fuertes visiones regionales no sólo para el concepto de "vecindad estratégica" (Strategic Neighbourhood). Pero sin embargo también parece que se prepara un despliegue del concepto: el establecimiento de esta zona como base para un papel global; también mantener la ampliación de la UE; un compromiso con la vecindad estratégica, asumiendo la responsabilidad por su seguridad. Estos serían algunos de los objetivos estratégicos de la UE, los cuales responden a una concepción estratégica establecida en la política de vecindad de la UE (ENP), con una serie de estrategias más concretas a través del instrumento de vecindad europeo. Desde estas posiciones, y cuando esta ENP unió la política llevada a cabo en el Mediterráneo con la antigua política de nueva vecindad hacia el este de Europa y el Cáucaso, mientras se realizaba un mecanismo a parte para las relaciones con Rusia $^{42}$, significó de facto cierto reequilibrio de la visión de la UE hacia el este y cierta marginación del Mediterráneo. En este sentido esta postura afectaba directamente a los intereses vitales de España, enfocados en el Mediterráneo y el Norte de África. Además de suponer un problema, la sobre-extensión de esta política, haciendo esta integración a partir de 2004, ésta une dos áreas muy diferentes que tienen una problemática dispar en todos los terrenos, y que también respondían a intereses y preferencias de diferentes Estados miembros de la UE. A la vez, y desde un punto de vista externo a la UE, parece que los proyectos estratégicos de otras grandes potencias no influyeron o no se consideraron fundamentales para la creación de percepciones y ciertas opciones estratégicas a largo plazo: en primer lugar, hacia Rusia, a pesar de políticas de cooperación y reaseguramiento. Sería muy difícil aceptar para Rusia la pérdida de control o influencia en su antiguo "Extranjero Cercano" (Near Abroad) o sus "Esferas de Influencia" 43 , un factor, aunque no el único, que ha tenido impacto

\footnotetext{
${ }^{41}$ Ver, por ejemplo: Copeland, Dale C.: "The Constructivist Challenge to Structural Realism: A Review Essay", International Security, vol. 25, $\mathrm{n}^{\circ} 2$ (Otoño 2000), pp. 187-212; Ruggie, J. G (1998): "What makes the World hang together? Neo-utilitarism and Social Constructivist Challenge", en Ruggie, J.: Constructing the World Polity: Essays of International Institutionalization, Londres, Routledge, pp. 1-40.

421994 Partnership and Co-operation Agreement (PCA); se ha producido una serie de intentos de puesta al día del acuerdo con Rusia de 1994 tras la creación del ENI, pero todos infructuosos (la cumbre de Khanti Mansiisk en 2008, la cumbre de Rostov de 2010); ver: http://eeas.europa.eu/russia/index en.htm.

${ }^{43}$ Este concepto ya no se utiliza realmente, sino más el de "Esfera de Influencia" u otros por los expertos como Transimperialismo; Wallander, Celeste: "Russian Transimperialism and Its Implications", The Washington Quarterly, vol. 30, no 2 (2007), pp. 117-118; García Cantalapiedra, David: "La política exterior de Rusia 1991-
} 
en las acciones de Rusia en Georgia en 2008 y ahora en Ucrania. Al mismo tiempo, otras grandes potencias han establecido sus visiones estratégicas para la zona como EEUU, con el Gran Oriente Medio, que se solapa en gran medida con la ENP. En este sentido no parece que hubo grandes problemas hasta la llegada de la Administración Bush, desarrollando planes más concretos a través del plan Broader Middle East and North Africa Initiative y el GUUAM (Georgia, Ucrania, Uzbekistán, Azerbaiyán y Moldavia). Además, es un objetivo estratégico forjar una nueva comunidad atlántica con Estados Unidos, también de acuerdo con la EGS 2013, además de reforzar y crear acuerdos estratégicos nuevos. Visiones estratégicas como el Pivot-Rebalance o el "Gran Medio Oriente " de EEUU, el ruso "Extranjero Cercano" o el chino de "Frontera Estratégica", son instrumentos de proyección de poder o de capacidad global. Si esa concepción sobre un vecindario estratégico responde a una visión de largo plazo, parece que ha contribuido a provocar percepciones y acciones no previstas, al menos en el caso ruso, debido a las áreas de solapamiento de interés (y la fricción) con otras potencias (incluida China) en Oriente Medio - Golfo Pérsico, el Cáucaso - Asia Central e incluso el Mediterráneo, Sahel - Cuerno de África. En el caso de China, ésta no se adhiere al concepto occidental de Westfalia de los Estados nacionales con fronteras fijas. Más bien, su concepto se basa en la "frontera estratégica" del panorama geopolítico, cuya flexibilidad territorial de fronteras se expandirá o se contraerá de acuerdo con la proyección del poder de una nación ${ }^{44}$.

Es evidente que la visión establecida en la Estrategia Europea de Seguridad de 2003 de la llamada periferia estratégica, que incluía los Balcanes, el Cáucaso, Oriente Medio y el Mediterráneo se ha intentado poner al día ${ }^{45}$. Pero la Unión Europea no pretende basarse principalmente o en gran medida de su capacidad para la proyección del poder: en este sentido olvida que este mecanismo actúa como sistema disuasorio en ciertas situaciones y escenarios, siendo un instrumento cuya utilidad en un sistema internacional como el actual tiene un valor de primer orden. En lugar de ello, la UE se enorgullece de ser un modelo para la prosperidad y mecanismo de resolución pacífico de problemas y reconciliación. Europa lidera este modelo como un ejemplo para el resto del mundo y éste tiene así una lógica poderosa detrás de esta noción, ya que actúa como un mecanismo de proyección a través de iniciativas de influencia. El problema es que la influencia del liderazgo europeo en otros países disminuye rápidamente con cualquier aumento de la distancia geográfica y la reducción de capacidad económica de la UE, y paradójicamente, los Estados en sus fronteras presentan toda una serie de problemas estratégicos de primer orden, que ya no se solucionan sólo con poder normativo. Esta postura en regiones vitales como Oriente Medio-Golfo Pérsico o del Cáucaso-Asia Central (origen del $70 \%$ de las importaciones de petróleo de la UE, contando con las importaciones procedentes de Rusia) no es sostenible, estratégicamente o desde un punto de vista de la resiliencia: ¿tiene capacidad de sostener la UE 600.000 millones de euros al año para el pago de las importaciones energéticas de la UE y su futuro incremento? La falta de capacidad real en la zona, como se demostrara durante la Primavera Árabe, la guerra civil de Siria y la crisis de Crimea y Ucrania con Rusia, es una falta de correlación entre los intereses vitales de la UE, el

2010: ¿de las "esferas de influencia” al Trans-imperialismo?, en CESEDEN (2011): "El futuro de las relaciones Rusia- OTAN". Monografías, Cuadernos de Estrategia, pp.17-39.

${ }^{44}$ Lin, Christine: "China's Strategic Shift Toward the Region of the Four Seas: The Middle Kingdom arrives in the Middle East", MERIA Journal, vol. 17, n 1 (Spring 2013); Lin, Christine: "Dragon in the Great Sea: China's Arrival in the "NATO Lake" of the Mediterranean", ISPSW/ETH Zurich (December 2012), paper first presented at U.S. Central Command's (USCENTCOM) "Scanning the Horizon", workshop in Tampa, Florida, on December 4, 2012; Lin, Christine: "The New Silk Road: China's Energy Strategy in the Greater Middle East", The Washington Institute for Near East Policy, Policy Focus, nº 109 (April 2011).

${ }^{45}$ Consejo Europeo: "Una Europa segura en un mundo mejor. Estrategia Europea de Seguridad", Bruselas (12 de diciembre de 2003); Consejo Europeo: "Informe sobre la aplicación de la Estrategia Europea de seguridad. Ofrecer seguridad en un mundo en evolución", Bruselas (11 de diciembre de 2008). 
concepto de vecindad estratégica y las capacidades e instrumentos. Esto puede hacer entrar a la UE en un dilema de seguridad, no quizá a corto o medio plazo, pero si a largo plazo. Pero al mismo tiempo, la idea de renovar la alianza con EEUU (reforzar la relación transatlántica sería mucho más efectivo) supone una opción y elección que tiene efectos en el aliado y los adversarios, y que supondría también un nuevo escenario estratégico.

Visto en este contexto estratégico, la ESN 2013 no define realmente el espacio euroatlántico, el cual tiene sentido en este grupo de visiones estratégicas, ya que realmente se encuadra dentro de la creación de nuevos escenarios o espacios estratégicos globales. La ESN 2013 establece que "La paz, la estabilidad y la seguridad en el espacio euro-atlántico es parte de la seguridad de España" (pág.16), y se declara: "La relación con Estados Unidos, el otro pilar de nuestra relación con las Américas, es clave en la gestión de este espacio”. Pero ¿qué es gestión de este espacio? ¿Hay Multipolaridad en el espacio euro-atlántico (entendido como Europa, Mediterráneo, África y Américas)? La ESN 2013 no parece creerlo. En estos términos debería de realizarse un análisis concreto y diferente para esta área. Si se incluye África en el espacio euro-atlántico, ¿se refiere a Norte, Sahel, Golfo de Guinea (prioritario para España y la UE, o a más áreas de África, incluido el cuerno de África o Sudáfrica, prioritario también para EEUU?)? Sin embargo hay intereses "vitales" de seguridad para España en el Norte de África, que podrían ser no compatibles, o no cubiertos por nuestro acuerdo de defensa con EEUU, por la OTAN, o incluso por la EU.

\section{España, EEUU y la UE en la seguridad del Espacio Euro-atlántico}

Existe una continuidad entre la descripción que realiza la estrategia de 2011 y la de 2013, copiando prácticamente el contenido y la literalidad del apartado dedicado a EEUU y las relaciones transatlánticas,

1-Los intereses vitales de España, esto es, paz, estabilidad y seguridad del llamado espacio euro-atlántico, que son parte de los intereses de seguridad de España, se repiten en ambas estrategias:

2011- "España convive en el espacio euro-atlántico con una larga serie de países vinculados por hondas raíces históricas y políticas e importantes relaciones económicas y comerciales......Que éste sea un entorno dotado de estabilidad, paz y seguridad resulta decisivo para el mundo y primordial para España".

2013- "La paz, la estabilidad y la seguridad en el espacio euro-atlántico es parte de la seguridad de España. La relación con Estados Unidos, el otro pilar de nuestra relación con las Américas, es clave en la gestión de este espacio y uno de nuestros principales activos en la dimensión internacional de nuestra seguridad."

Claramente esto significa continuidad, aspecto muy positivo, ya que demuestra un acuerdo en una política de Estado, aunque su escaso desarrollo también denota un problema que se puede observar a lo largo del desarrollo de la estrategia, que es la tendencia a ser más un documento de consenso político y declarativo/informativo, que una estrategia de seguridad con mayor calado y profundidad. No obstante, hay un aspecto de mayor normalidad en la importancia y el tratamiento de esta relación en la estrategia de 2013. De hecho el marco estratégico global 
que parece considerar este punto es que EEUU sigue siendo la única superpotencia "Dentro de este marco, Estados Unidos sigue siendo la mayor potencia mundial en términos económicos, militares, científicos y culturales", cuestión al menos paradójica cuando desde 2004 los gobiernos socialistas y el propio Zapatero mantenían posturas más próximas a una visión de multipolaridad, postura que, de hecho, mantiene la estrategia de 2013. Dado el esfuerzo del último gobierno socialista en mejorar las relaciones transatlánticas, pone énfasis en los aspectos que hacen más profunda la relación entre ambos Estados y los instrumentos comunes bilaterales de cooperación: "Los dos países compartimos valores comunes y estamos unidos por unas estrechas relaciones humanas, históricas, culturales y lingüísticas, económicas, políticas y militares. El Convenio de Cooperación para la Defensa entre España y Estados Unidos y el Comité Bilateral de Alto Nivel Hispano-Norteamericano (CBAN) garantizan la coordinación y cooperación bilateral en el ámbito de la Defensa" ${ }^{\text {"6 }}$. Este último párrafo sí hace referencia al Convenio de defensa con EEUU que la ESN 2013 no menciona. Ya en un discurso del Presidente Zapatero en $2008^{47}$, y la propia Directiva de Defensa Nacional DDN 2012 $2^{48}$, primer documento de seguridad del nuevo gobierno, se enfatizaba como prioritaria la relación con EEUU y a la Alianza Atlántica como el vínculo prioritario para España en seguridad y defensa. Estos aspectos no se incluyen en 2013, aunque parece que se da una importancia a otras esferas y, de carácter general, a la relación bilateral, no sólo en el ámbito de la seguridad, aunque ésta sigue siendo la primordial según lo establecido en ambas estrategias. Pero hay una indefinición de lo que significa el espacio euro-atlántico, aunque hay que suponer que se refiere a EEUU, Europa, Iberoamérica y África, aunque ambas estrategias hablan de "una visión ampliada de las relaciones transatlánticas"

Sin embargo, está claro que en ambas estrategias se considera a EEUU vital para la dimensión de seguridad de España y como socio en términos globales:

2011- "Además de un aliado sólido, es un socio indispensable y prioritario"... "Con Washington podemos impulsar una visión ampliada de las relaciones transatlánticas en el ámbito de la seguridad que incluyan, además de Europa, Canadá y Estados Unidos, a Iberoamérica por un lado, y el continente africano por el otro. Un nuevo marco que nos permitiría afrontar de manera más efectiva amenazas y riesgos compartidos como el terrorismo, los tráficos ilícitos o el crimen"

2013- "Estados Unidos es uno de nuestros aliados más relevantes y un socio indispensable y prioritario para la gestión de los retos y oportunidades que presenta el mundo globalizado. El importante crecimiento de la población hispanohablante de Estados Unidos es un factor determinante en esta relación. Estados Unidos es el interlocutor de referencia en el objetivo de conseguir una visión amplia de las relaciones transatlánticas, que tenga en cuenta la seguridad tanto en América como en el continente africano. Esta visión, de la que forma parte una más estrecha relación con Canadá -actor a tener en gran consideración en nuestra relación transatlántica-, conducirá a un nuevo marco que nos permitirá afrontar de manera más efectiva los riesgos y amenazas compartidos".

\footnotetext{
46 "Estrategia Española de Seguridad" (2011), p. 26.

${ }^{47}$ Rodríguez Zapatero, J.L.: "En interés de España: una política exterior comprometida", Real Instituto Elcano, ARI (17 de junio de 2008), en http://www.redri.org/new/images/archivos/zapatero_politica_exterior_espana_2008.pdf.

48 "Directiva de Defensa nacional 2012", Presidencia del Gobierno (Julio 2012), en http://www.lamoncloa.gob.es/NR/rdonlyres/0E911A5C-F0F6-490F-82801AE0EDC539CE/210550/DIRECTIVADEDEFENSANACIONAL2012.pdf.
} 
También, es primordial entender que "En el espacio euro-atlántico, la OTAN resulta determinante para la seguridad de la región representa una dimensión esencial de nuestra defensa. Para preservar su eficacia, debe continuar adaptándose a una realidad cambiante, en la que los riesgos y las amenazas aumentan y se diversifican continuamente. A tal fin, debe desarrollar de manera equilibrada y con una visión amplia de la seguridad las tres tareas fundamentales que establece su nuevo concepto estratégico: la defensa colectiva, la gestión de crisis y la seguridad cooperativa". En este sentido, la reducción de recursos en España para la seguridad y la defensa y "la disminución del presupuesto dedicado a Defensa de los países de la Alianza y el paralelo incremento del gasto militar o la inversión mantenida en otros países conduce a un desequilibrio estratégico. Para España, esto supone un doble desafío, en cuanto decrece el paraguas disuasivo colectivo y es un reto asegurarse unas capacidades críticas propias con las que poder hacer frente a los riesgos y amenazas".

\section{Alternativas para España ante el impacto del dilema de seguridad: ¿reestructuración y reforzamiento de alianzas?}

Esta dinámica claramente responde a lo que los estudios de seguridad llaman un dilema de seguridad en la política internacional: la incertidumbre relativa a las motivaciones actuales y futuras de otros actores en una situación donde se está bajo la influencia de la anarquía en la estructura del sistema internacional alimenta este dilema de seguridad y aparece según los Estados toman medidas para aumentar su seguridad que otros perciben como reducciones en la suya. Esto dispara conductas reactivas que, finalmente, socaban la seguridad de todos los actores y hacen la guerra mucho más probable. Robert Jervis señala que las diferencias entre los Estados, especialmente en la prioridad dada a la seguridad en relación con otras preocupaciones internas y el grado de la percepción de la amenaza, afectarán la severidad del dilema de seguridad y formarán los costes asociados con el llamado sucker's payoff. La geografía, los compromisos con creencias particulares y la tecnología también perjudicarán el grado con el cual aparecerá el dilema de seguridad. Específicamente, el equilibrio ofensivadefensa y la habilidad para diferenciar entre estrategias defensivas y ofensivas alterarán la probabilidad de conductas de espirales de seguridad-inseguridad ${ }^{49}$. El dilema de seguridad se asume como una de los principales parámetros del realismo defensivo dentro de la teoría de las relaciones internacionales, junto con la teoría de la ofensa-defensa, los procesos de percepción y la política interna. Aun así, el concepto del dilema de seguridad es aceptado en todas las aproximaciones del realismo defensivo. Este concepto refleja la naturaleza en buena parte anárquica del sistema internacional que produce incertidumbre. Los Estados no pueden estar seguros sobre de las intenciones presentes y/o futuras de los otros y buscan llevar a cabo políticas de búsqueda de seguridad (security-seeking policies). Pero estas lograrán que otros Estados se sientan amenazados y harán, a su vez, que incrementen su propia seguridad, reduciendo, así, la de todos.

La formación de alianzas ha sido un mecanismo a través del cual se ha buscado enfrentarse al dilema de seguridad: los problemas de la incertidumbre, los procesos de percepción y, finalmente, el proceso autodestructivo de la búsqueda de seguridad en un sistema internacional anárquico $^{50}$. Así, de acuerdo con la teoría del dilema de seguridad,

\footnotetext{
${ }^{49}$ Jervis, Robert: "Cooperation under the Security Dilemma", World Politics, vol. 30, no 2 (Enero 1978), pp. $168-214$.

${ }^{50}$ Snyder, Glenn: "The Security Dilemma in Alliance Politics", World Politics, vol. 36, no 4 (Julio 1984), pp. 461-462.
} 
también los Estados podrían enfrentarse a un dilema de seguridad en las alianzas, y este dilema será más severo en sistemas multipolares que bipolares o unipolares: esto se debería a que los sistemas multipolares son menos estables.

Como la creación de una alianza es un incentivo general generado por la estructura del sistema internacional, los Estados buscarán aliados o se abstendrán de crear o entrar en alianzas, y existiendo, además, asimetrías en las capacidades e intereses de seguridad diferentes, la formación de las alianzas significarán costes y ganancias. Los objetivos principales a la hora de crear alianzas serán formar parte de la más poderosa y maximizar su pertenencia, aunque habrá otros intereses importantes en el proceso de negociación de creación de la alianza: intereses generales y particulares, los cuales pre-dispondrán a los estados a alinearse con determinados Estados. Los intereses generales y particulares están relacionados con el sistema internacional y la posición geográfica de cada Estado.

Desde este punto de vista, si pensamos en la alianza con EEUU, la disuasión extendida de EEUU en Europa perdió su razón de ser tras el fin de la URSS, y Europa dejó de ser el centro de la política estratégica de EEUU; hay otras áreas como Asia Oriental o el Gran Oriente Medio que demandan más atención. Sin embargo, ya la Estrategia Europea de Seguridad de 2003 y las estrategias de seguridad nacional norteamericanas de 2002, 2006 y 2010 identificaban un sistema internacional con amenazas comunes tales como el terrorismo, las armas de destrucción masiva y los competición regional. Los intereses particulares pueden crear conflictos o afinidad con otros Estados y establecer un patrón tácito de alineamiento antes de las negociaciones en la alianza. Así, caracteres como los contenidos del poder, ideología, prestigio y economía pueden crear un número de afinidades, dando a los Estados expectativas que serán apoyadas por aquellos con quién se comparten intereses: por ejemplo, España apoyó a EEUU en la Iniciativa Global contra el Terrorismo Nuclear (IGTN), lanzada conjuntamente por los presidentes de Estados Unidos y Rusia en 2006 para cuyo Grupo de Aplicación y Evaluación España fue elegida en 2010 como primer país coordinador. También "apoyó los esfuerzos internacionales para limitar la proliferación de misiles de largo y corto alcance, susceptibles de ser utilizados para el lanzamiento de armas de destrucción masiva. España apoya, en este sentido, la universalización del HCOC (Código Internacional de Conducta de La Haya contra la Proliferación de Misiles Balísticos). Además, se secundará el desarrollo de una capacidad autónoma de defensa antimisiles en el marco de la OTAN y su Programa de Defensa Antimisiles y la armonización del principio de la disuasión mínima con los compromisos internacionales de desarme" ${ }^{, 51}$.

España ha apoyado la política aliada y de EEUU en Afganistán, mantiene las operaciones navales de vigilancia de la OTAN en el Mediterráneo, el despliegue del programa antimisiles con el despliegue en Rota de 4 cruceros o fragatas AEGIS norteamericanos y la revisión de la política nuclear de la OTAN siguiendo las posturas de EEUU (2010 NPR) y Alemania principalmente, en cuanto al desarme de la Alianza de las armas nucleares tácticas y el valor del arma nuclear en el nuevo concepto estratégico de la OTAN de 2010. Pero los conflictos externos y las afinidades reducen, pero no eliminan, la indeterminación a la hora de elegir aliados o adversarios debido al proceso de subestimación por parte de los aliados de conflictos con terceros Estados o adversarios. Por ejemplo, la percepción y valoración del terrorismo o la invasión de Irak se vieron de forma diferente por parte de EEUU y los estados europeos. Una vez creadas, las alianzas se encuentran con el dilema secundario en la alianza, esto es, cómo los aliados se mueven entre la cooperación y la deserción (entrapment-defection). Jervis analiza este proceso usando otros términos tales

\footnotetext{
51 "Estrategia de Seguridad Nacional" (2013), p. 46.
} 
como firmeza y acomodación (aunque para explicar los problemas de las teorías de la espiral y la disuasión), y señala que la elección entre uno u otro depende de la estimación que se haga de los objetivos vitales del adversario o del aliado ${ }^{52}$. Christiansen y Snyder hablaran de "chain gang" y "buckpassing”. En este sentido, es necesario analizar cómo los aliados tratan con los adversarios e interactúan con el juego del adversario, porque ambos juegos se dan al mismo tiempo y se complementan el uno al otro ${ }^{53}$. Cooperación significará un firme compromiso general firme y apoyo total en conflictos específicos con los adversarios. Las estrategias de fuerte compromiso detendrán al adversario, aumentaran la reputación de firmeza, pero reducirán la capacidad de negociación sobre el aliado. Por ejemplo, los aliados europeos de la OTAN promovieron el uso del artículo V del Tratado del Washington tras el 11-S: la mayoría de los aliados europeos, especialmente el Reino Unido, España e Italia, apoyaron la invasión de Irak. El compromiso firme hace a los aliados menos influyentes: la Guerra Global al Terror (GWOT) y la Operación Enduring Freedom en Afganistán fueron lanzadas con el total apoyo europeo y español. Estas estrategias reducían otras opciones de alineamiento con otros Estados (Rusia o China, por ejemplo) y, al mismo tiempo, reforzaban la posibilidad de que las alianzas del adversario pudieran ser consolidadas (por ejemplo, la existente entre Siria-IránHezbolá).

Una deserción o abandono o "buckpassing” pueden significar un compromiso débil y ningún apoyo en conflictos específicos con adversarios. Hay diferentes variantes de esta postura: por ejemplo, realineamientos, des-alineamientos, fallos que proporcionan compromisos explícitos y fracasos a la hora de suministrar apoyo en contingencias donde este se espera. La ambigüedad también aumenta el riesgo de abandono, es decir, algunos de los aliados tratan de evitar la alineación y la distribución de la carga frente a una amenaza creciente, a la espera de no tener gastos innecesarios y/o para mejorar sus posiciones relativas en relación respecto a sus aliados en el futuro. Por otra parte, el desarrollo progresivo de una seguridad de la UE y de una política de defensa crea visiones alternativas y estrategias para la UE, para los intereses generales y particulares ${ }^{54}$; desde el final de la Guerra Fría, Europa no es la prioridad de la política global de EEUU, a pesar de que sigue siendo un elemento principal, pero la visión de la superioridad militar puede crear una tendencia en la UE (sobre todo en algunos de sus Estados) de pasar la pelota a EEUU ${ }^{55}$. Pero tras la crisis de Ucrania con Rusia, y la petición de firmeza de los Estados del centro y este de Europa, junto con los bálticos, e incluyendo la tendencia de Finlandia y Suecia hacia la Alianza Atlántica, hay una tendencia hacia un "chain gang".

El poder de negociación sobre los aliados se ve reforzado por compromisos débiles o ambiguos, pero los incentivos o desincentivos para la elección también se ven in-fluidos por algunos factores determinantes: la dependencia relativa de los socios en la alianza, el grado de interés estratégico en la defensa de unos a otros, cómo de explícito es el acuerdo de alianza, el grado en que los intereses de los aliados en conflicto con el adversario se comparten y la conducta histórica reciente ${ }^{56}$. Sin embargo, estas mismas capacidades, dado la situación en Ucrania pueden ser utilizadas para reforzar un refuerzo de la alianza. Además, en el juego del adversario, compromisos firmes tienden a fortalecer el poder de negociación vis-à-vis del aliado, es decir, la influencia sobre el adversario se ve reforzada por un compromiso firme, explícito. En este sentido, los acuerdos explícitos, un alto grado de intereses compartidos en

\footnotetext{
${ }^{52}$ Jervis, "Cooperation under the Security Dilemma", op. cit., p. 113.

${ }^{53}$ Snyder, "The Security Dilemma in Alliance Politics", op. cit., p. 468.

${ }^{54}$ Posen, Barry: "European Union Security and Defense Policy: Response to Unipolarity?", Security Studies, vol. 15, nº 2 (Abril-Junio 2006), pp. 149-186.

${ }_{55}$ Christensen y Snyder, op. cit., pp. 139.

${ }^{56}$ Glenn Snyder, "The Security Dilemma in Alliance Politics", op. cit., pp. 471-77.
} 
conflicto con el adversario y el comportamiento reciente histórico común apoyaría una estrategia de fuerte compromiso de la alianza. Desde este punto de vista, existe un gran número acuerdos entre EEUU y España bilateralmente (y a través de Europa, no solo a nivel de seguridad, sino la Nueva Agenda Transatlántica de 1995 o la negociación de un Tratado de Libre Comercio e Inversiones Transatlántico, TTPA). Así, en el juego adversario, el compromiso de la UE o de EEUU puede eliminar de antemano otras opciones. El fortalecimiento del compromiso de la España/UE con EEUU tiende a excluir otras opciones alternativas de alianzas para la UE. En el caso de Rusia y Ucrania, si Rusia tiene objetivos expansionistas, una política de firmeza mejorará la reputación, pero una estrategia de conciliación produciría una caída de efecto dominó: Rusia, China y otras potencias como Irán podrían interpretar como debilidad cualquier propuesta de la UE y así presionar más sobre estas cuestiones presentes y futuras.

\section{Conclusiones}

La estrategia de seguridad nacional de 2013 establece una clara continuidad respecto a la estrategia de 2011 respecto al tratamiento de la alianza y las relaciones con EEUU, aspecto muy positivo, ya que demuestra un acuerdo en una política de Estado, aunque su escaso desarrollo también denota un problema que se puede observar a lo largo del desarrollo de la estrategia, que es la tendencia a ser más un documento de consenso político y declarativo/informativo, que una estrategia de seguridad con mayor calado y profundidad.

\subsection{Factores generales}

6.1.1. En algunos aspectos esta falta de análisis en profundidad marca la ausencia de factores claves y el uso de "lugares comunes" que denota a veces el documento. Hemos visto que los supuestos o suposiciones realizados sobre la interdependencia entre las elecciones propias y la de los otros hacen que probablemente se hayan producido un impacto negativo en la dinámica estratégica global y regional, y probablemente en ciertos resultados. En este sentido, el análisis de ciertos factores como la Gran Recesión o el declive relativo de EEUU, que afectan a la estructura del sistema, junto con su cambio de políticas, en un sentido de reequilibrio exterior más que interior, y el ascenso de nuevas potencias con el declive de otras, ofrece, junto con su realineamiento en el sistema internacional, una idea de multipolaridad o de sistema pluricéntrico. Sin embargo, ya que la polaridad del sistema deviene de su estructura, y no de las interacciones de los actores del sistema, habría que reconsiderar los posicionamientos sobre multipolaridad o pluricentralidad, o al menos, repensar qué significa, $\mathrm{y}$, sobre todo, qué efectos tiene en la toma de las decisiones de los actores. Como hemos visto, concepciones y percepciones erróneas pueden favorecer políticas y estrategias que lleven, como mínimo al declive y la irrelevancia o, en el peor de los casos, a conflictos y a la guerra.

6.1.2. A la vez, en el marco general estratégico y su conceptualización establece conclusiones o conceptos altamente discutibles desde el punto de vista teórico y práctico. En este contexto de competición regional y trasformación del entorno de seguridad, la conducta de España que permita enfrentarse al dilema de seguridad causado por la pérdida de capacidades, podría caer en un peligroso "buckpassing", al evaluar el entorno estratégico y de seguridad erróneamente, ya que no percibe el proceso de transición que acontece en la estabilidad estratégica, y considerar que la seguridad propia no está ya interrelacionada con la de EEUU como antes. Probablemente la crisis con Rusia obligará a una reconsideración de esta postura buscando un reforzamiento de las alianzas más en la línea de un "chain gang”. 
6.1.3. También hay condicionamientos externos tales como el engarce con la UE y la OTAN que necesariamente impactan de manera definitiva en el documento. Si el sistema internacional ha cambiado o está en proceso de cambio o hay una percepción determinada sobre ese cambio, con las condiciones que hemos visto antes, habrá un incentivo general para la creación de alianzas, y algunos Estados se aliarán con otros Estados de acuerdo con la lógica del dilema de seguridad. Sin embargo, los alineamientos son el resultado de un proceso que es, generalmente, indeterminado. Esta indeterminación se puede reducir, pero no eliminar, a causa de los intereses generales y particulares. Desde este punto de vista, la alianza entre EEUU y España ha estado experimentando un proceso de ajuste estructural. La alianza actual, sin embargo, no es completamente nueva y persistirían algunas de las características de la alianza de la Guerra Fría, como los que reflejan ciertos intereses generales y particulares que predisponen a EEUU y España a alinearse uno con otro, al igual que a la UE con EEUU. La disuasión extendida de EEUU en Europa no era necesaria, ya que no había ninguna espiral de inseguridad y Europa ya no estaba en el centro de la política estratégica de EEUU. Sin embargo, la dinámica en el sistema internacional y los factores que afectan al dilema de seguridad crean un incentivo general para formar (o mantener) una alianza. Además, hay un núcleo de los precedentes y las relaciones (la ideología democrática y los sistemas políticos, apoyo de la OTAN, los valores comunes) que condicionan el proceso de negociación de la alianza, que predispone a ciertas alianzas y contra otras.

6.1.4. Hay conceptos innovadores y de una profundidad estratégica clave como el espacio euro-atlántico que aún denotan indefinición acerca de lo que significa este espacio en términos incluso geográficos y de las interacciones de los actores EEUU, Europa, Iberoamérica y África, aunque ambas estrategias (2011 y 2013) hablan de "una visión ampliada de las relaciones transatlánticas". No obstante, está claro que en ambas estrategias se considera a EEUU vital para la dimensión de seguridad de España y como socio en términos globales.

6.1.4.1. Este concepto debería de ser desarrollado como un objetivo vital, que en cierta manera, sustituyera las llamadas históricas "inclinaciones" de España, esto es, Europa, Mediterráneo, Latinoamérica y EEUU. Es de máxima urgencia la reconsideración integrada de nuestra visión estratégica que permita poner al día nuestros intereses, su construcción e interrelación; por ejemplo, y en esta dirección es llamativo que el Ministerio de Asuntos Exteriores tenga una dirección general que reúne América del Norte con Asia.

6.1.4.2. Segundo, reducir nuestras ambiciones al mínimo en otras áreas necesariamente por causa de nuestras capacidades; reconsiderar otras áreas de interés a largo plazo; probablemente, y a pesar de nuestras excelentes relaciones, España hoy tiene poca capacidad de influencia en Oriente Medio. A la vez, se podría hacer una aproximación selectiva en algunas áreas, concentrando nuestros recursos en Estados donde España tenga más opciones a largo plazo y/o con los que comparta lazos históricos, políticos o económicos de gran potencialidad, como podría ser el caso de Filipinas, Singapur o Australia en Asia.

6.1.4.3. finalmente, reconsiderar nuestra política de alianzas, considerándola un valor en alza ante la falta de capacidades, cambio de enfoques y dinámicas del sistema internacional a largo plazo. En este sentido, Estados como por ejemplo Portugal, Italia, Gran Bretaña, Argelia, Canadá, Brasil y los Estados de la Alianza del Pacífico deberían de ser potenciados. 


\subsection{Factores particulares}

Seguramente hay dos aspectos relativos al desarrollo del documento que más llaman la atención y, desgraciadamente, sesgan sus expectativas:

6.2.1. Relativo a la consideración de la transformación de la estabilidad estratégica y de la política de seguridad. Con respecto a las concepciones de seguridad que se encuentran en el los planteamientos españoles y europeos, el principal problema no es la definición de la estructura del sistema internacional como multipolar. Esto es discutible, en la teoría y en la práctica, pero sí es urgente reconocer que el entorno de seguridad ha cambiado drásticamente, no sólo debido a varios desafíos, amenazas y diferentes actores, sino también a que el factor principal de este entorno en términos de seguridad es el cambio a un mundo donde domina la Ofensiva, debido, sobre todo, a la ciberguerra, dada su interrelación con los sistemas espaciales, armas de destrucción masiva, la defensa antimisiles, las capacidades convencionales Global Strike, y la robotización del campo de batalla. Esto ha cambiado, por ejemplo, el significado (o incluso la utilidad) de la disuasión y la capacidad para mantener el equilibrio ofensa-defensa y su diferenciación, en un sistema internacional muy dinámico, con nuevas alianzas y alineamientos, la falta de incentivos y la reducción de la convergencia de intereses y aumento de la competencia, hace que el sistema internacional sea propenso a visiones ofensivas, y acciones agresivas y posturas más beligerantes, incluso desde un punto de vista económico y tecnológico.

6.2.2. El silencio del documento acerca del Convenio de Cooperación en Defensa de 1988 con EEUU. No parece que tenga sentido la consideración de la alianza con EEUU como uno de nuestros valores internacionales más importantes, con la ausencia del marco general de esta relación como factor básico en el análisis del documento y de la relación con EEUU. Desde cierto punto de vista, la ausencia del convenio de 1988 parece denotar un transfondo político que refleja, no un alejamiento equidistante de EEUU en relación a la UE en términos de la importancia y profundidad de la relación (que no tendría sentido en función de lo que dice la ESN 2013), sino más bien en una lectura de política interna relativa a evitar una visión demasiado "atlantista", que pudiera relacionarse con las posiciones de los gobiernos españoles entre 1996 y 2004.

\subsection{Reflexiones finales}

Durante la bipolaridad de la Guerra Fría, los aliados occidentales estaban bajo la amenaza soviética; esto creó una espiral de inseguridad que, a su vez, produjo una espiral integradora ("chain gang") con un acercamiento cada vez más estrecho entre los aliados debido al miedo al adversario, que, por tanto, redujo el riesgo de abandono de la alianza. Este tipo de amenaza existencial ya no existe o, al menos, no existe una percepción común de una amenaza tan grave como las procedentes de la URSS durante la Guerra Fría. De hecho, son las percepciones y los incentivos estratégicos las que ofrecen las diferentes opciones. Así, aunque el incentivo para sostener la integración en espiral y las estrategias de fuerte compromiso que existieron durante la Guerra Fría no existen o no son tan fuertes, a pesar de la conducta de Rusia, China y otros actores junto con otros actores no estatales y desafíos globales, otros factores como la reducción de recursos y capacidades, y el declive posicional estratégico regional y global) crearían los incentivos para restaurar ese acercamiento.

El principal problema dentro de la alianza EEUU-Europa (España) descansaba en un desacuerdo acerca de cómo lidiar con el juego del adversario dentro del dilema de seguridad, y de cómo esto afecta a la negociación intra-alianza (dilema de seguridad secundario). Cada 
parte tiende a adoptar diferentes enfoques y estas estrategias afectan directamente el juego de la alianza. EEUU y los aliados europeos tienen imágenes divergentes de los motivos y las intenciones del adversario. Al mismo tiempo, algunas potencias europeas tienden a ver más peligro en la dinámica del conflicto que en el adversario, aunque otras no, y otras pueden tender a un "buckpassing”. EEUU puede poner menos énfasis en la moderación después de las actuaciones de China en Asia y de Rusia en Europa, sin olvidar la política de ambos en Oriente Medio. Los europeos (pueden) compartir esta visión de EEUU y utilizar una estrategia de compromiso con el fin de mantener la solidaridad con EEUU.

España hoy no tiene capacidades ni una posición regional suficientemente fuerte y firme (en la UE, OTAN y en el Mediterráneo) como para realiza un "buckpassing" a los aliados de estas organizaciones. Además aunque tuviéramos un desacuerdo en cómo lidiar con la formación de los intereses de las alianzas y también con el problema del adversario, la posición relativa más débil de España en estas organizaciones lleva a tener que establecer conductas de "bandwagoning" y "chain gangs" generalmente (excepción es el caso de Gibraltar y Kosovo). Sin embargo, estas no comportan necesariamente que los intereses vitales de seguridad de España estén cubiertos. Es más, un factor vital para compensar este problema es la alianza con EEUU

En la visión europea, que paradójicamente reforzaba los temores europeos, temían verse atrapados o ser arrastrados a un conflicto solo por un interés de EEUU que ellos no compartiesen o que compartiesen solo parcialmente. Paradójicamente, presumían posibilidades de verse atrapados en un conflicto en un área que era prioritaria para la Política de Vecindad y el Vecindario Estratégico, pero debido a una ampliación de la OTAN a Ucrania y Georgia, o por una política agresiva norteamericana en el Gran Oriente Medio o a través de GUUAM, pero no por la propia política de la UE allí. Posteriormente se produjo la invasión rusa de Georgia. Los europeos han tratado de escapar o minimizar los riesgos de este compromiso-atrapamiento, sin grave riesgo de abandono de EEUU, a pesar de aceptar el abandono parcial en forma de retirada de las tropas, o el papel secundario de EEUU en Libia. Afectando a la posición y la política de España, la UE se ha debatido entre la cooperación y la deserción en las negociaciones en la alianza principalmente debido a la influencia de ciertos aspectos de la estructura del sistema internacional (por ejemplo, la ausencia de una percibida amenaza existencial que crearía una espiral de integración dentro de la alianza), una reducción percibida en el compromiso de EEUU, y, sobre todo, la influencia del juego del adversario en el dilema de la alianza secundaria (lo que refleja diferentes percepciones sobre las amenazas). Desde el final de la Guerra Fría, con una unipolaridad clara, dividendos reales de la paz y la ausencia de percepción de las principales amenazas, no hubo percepciones claras de los cambios y las necesidades de ajuste, pero, inevitablemente, el dilema de la alianza es más grave en una situación de alta incertidumbre y con su impacto negativo en el sistema internacional, junto a los factores que hacen más severo el dilema de seguridad. Los miembros de la alianza entre EEUU y Europa han respondido de manera diferente en el juego del adversario en función de la percepción de amenaza, ya que no planteaban los factores estructurales como un impacto fundamental en el dilema de seguridad, y esto crea resultados diferentes en el juego de la alianza al existir incentivos estratégicos diferentes. Según el modelo del dilema de seguridad en las alianzas, los nuevos incentivos estratégicos en términos de la estructura del sistema internacional, las percepciones y la conducta de los actores, han empezado a promover la convergencia de las políticas hacia posturas de "chain gang”, aunque aún hay posturas de "buckpassing" en algunos aliados europeos. En esta situación la estrategia de España se enfrenta a la necesidad de reforzar o volver a crear alianzas con Estados Unidos y con otros miembros del "Club Unipolar". En este sentido, España tendría que hacer establecido un análisis más amplio y profundo del significado de la 
alianza con EEUU, los incentivos estratégicos para España, y una serie de opciones previas que se podrían introducir en la política de seguridad española, relacionadas con el espacio euro-atlántico. Para ello sería de máxima utilidad promover una reforma del Convenio de 1988, amén de otros acuerdos en otras áreas con EEUU, en una línea de profundización de la Declaración Conjunta de 2001. Ya se han dado toda una serie de pasos en este sentido en los últimos años, pero por ejemplo se podría plantear la opción de establecer el AFRICOM en España, reforzando ya una serie de pasos dados por EEUU y España en cuanto a la importancia estratégica del área en relación al espacio euro-atlántico. 